\title{
Influência da aplicação tópica de géis de flúor na rugosidade superficial de cimentos de ionômero
}

\author{
Influence of topical applications of fluoride of gels of the surface roughness of glass ionomer cements
}

Renally Bezerra Wanderley e Lima

Mestra em Materiais Dentários pela FO/Unicamp Piracicaba

Julyana de Araújo Oliveira

Mestra em Odontologia pela Universidade Federal da Paraíba (UFPB)

\section{Ana Karina Maciel Andrade}

Fábia Danielle Sales da Cunha Medeiros e Silva

Professoras Adjuntas do Departamento de Odontologia Restauradora da UFPB

Rosângela Marques Duarte

Professora Associada do Departamento de Odontologia Restauradora UFPB

\section{Resumo}

Avaliar a morfologia de superfície de quatro CIVs (cimentos de ionômero de vidro) quando submetidos à ação tópica do flúor fosfato acidulado a 1,23\% e gel de fluoreto de sódio neutro a $2 \%$. Foram confeccionados 10 espécimes de cada CIVs (Ketac Molar Easymix, Maxxion R, Vitro Molar e Vitremer). Um ensaio de rugosidade foi efetuado antes e após aplicação tópica de gel de flúor. Os dados obtidos foram analisados através do teste de Tukey e do teste T. Os valores de rugosidade apresentados pelos materiais, segui a ordem descrescente: Maxxion>Ketac Molar Easy Mix> Vitro Molar. A aplicação tópica de flúor acidulado apresentou alterações de superfície nos materiais avaliados.

Palavras-chave: cimentos de ionômero de vidro; flúor; propriedades de superfície.

\section{ABstract}

To evaluate the surface morphology of four glass ionomer cements when submitted to $1.23 \%$ acidulated phosphate fluoride topical application and $2 \%$ sodium fluoride. Ten specimens of each material (Ketac Molar Easymix, Maxxion R, Vitro Molar and Vitremer) were made. Surface roughness testing was made before and after topical application of fluoride. Data were analyzed statistically by Tukey's test and T's test. Maxxion presented the biggest variation on morphological standard after treatment with acidulated gel, continuing, in decreasing order, by Ketac Molar Easy Mix and Vitromolar. The topical acidulated fluoride presented surface alterations in all evaluated materials.

Keywords: glass ionomer cements; fluoride; properties of surface.

\section{Introdução}

O s cimentos de ionômero de vido (CIVs) foram desenvolvidos, em 1971, por Wilson \& Kent, a partir do pó do cimento de silicato que, misturado ao líquido do ácido poliacrílico modificado, análogo ao utilizado nos cimentos de policarboxilatos, originou um cimento translúcido. Os CIVs foram idealizados como substitutos dos cimentos de silicato e nesta categoria apresentam propriedades semelhantes, porém com vantagens adicionais. Uma das vantagens desses materiais está na capacidade de adesão ao dente devido à troca de íons entre o material e a estrutura dentária. Além disso, os CIVs apresentam excelente biocompatibilidade além do relevante benefício da liberação de flúor (1).

Esses cimentos representam importante opção de material restaurador em Odontologia. Sua adesão à estrutura dental que reduz a infiltração marginal, somada à liberação de flúor é capaz de inibir o metabolismo de micro-organismos acidogênicos e favorecer a remineralização dental, diminuindo a ocorrência de cárie secundária (2). No entanto, uma limitação dos CIVs convencionais está diretamente relacionada à ação de soluções com baixo $\mathrm{pH}$, como por exemplo, o ácido cítrico, que, quando aplicadas diretamente à superfície de restaurações, poderiam deteriorá-las, tornando esses materiais susceptíveis às falhas clínicas (1). A capacidade de liberação de flúor dos CIVs pode ser parcialmente recuperada, tendo em vista que estudos mostram que os de cimentos de ionômero de vidro convencionais e modificados por resina são capazes de adsorver flúor dos dentifrícios, soluções fluoretadas e géis, agindo como um sistema lento de deposição destes íons diretamente no dente (3-6).

A aplicação de flúor tópico sobre restaurações de cimentos de ionômero de vidro é capaz de restituir parte do flúor liberado pelo material restaurador. No entanto, como os géis de fluorfosfato acidulado possuem ácido fosfórico e ácido fluorídrico, que são condicionadores de vidro, o uso desses produtos pode afetar a superfície não só dos cimentos ionoméricos, como de outros materiais restauradores (2). Embora a aplicação tópica de flúor gel e flúor verniz seja um procedimento estabelecido na Odontologia Preventiva, à recarga forçada de fluoretos em ionômeros de vidro modificados por resina pode ocorrer à custa de um aumento da rugosidade superficial e da deterioração do material restaurador ao longo do tempo, influenciando sua morfologia (7).

A resistência ao desgaste e a rugosidade superficial no ambiente oral são importantes critérios para determinar e predizer a deterioração de materiais restauradores. Portanto, as características superficiais de restaurações com o cimento de ionômero de vidro são particularmente importantes, uma vez que superfícies rugosas podem promover uma colonização bacteriana mais rápida. Assim, afetando as propriedades anticariogênicas e os princípios condizentes a este material restaurador (8).

Assim, o objetivo do referido estudo é avaliar a morfologia de superfície de quatro cimentos ionoméricos (Ketac Molar Easy Mix, Vitremer, Vitro Molar e Maxxion R) quando submetidos à ação tópica do flúor fosfato acidulado a $1,23 \%$ bem como do gel de fluoreto de sódio neutro a $2 \%$. 
A hipótese testada é que a morfologia de superfície dos cimentos ionoméricos é alterada após a aplicação tópica do flúor fosfato acidulado a $1,23 \%$ e do gel de fluoreto de sódio neutro a $2 \%$.

\section{Material e Método}

Os materiais utilizados neste estudo, juntamente com sua composição, fabricante estão listados no quadro I.

Quadro I. Materiais, classificação, fabricante e descrição da composição

\begin{tabular}{|c|c|c|c|c|}
\hline Material & Fabricante & $\begin{array}{l}\text { Composição das } \\
\text { particulas }\end{array}$ & $\begin{array}{l}\text { Composição do } \\
\text { liquido }\end{array}$ & Classificação \\
\hline $\begin{array}{l}\text { Ketac Molar } \\
\text { Easymix }\end{array}$ & 3M ESPE & \begin{tabular}{|l|} 
Vidro de \\
fluorsilicato de \\
alumínio, lantânio e \\
cálcio, ácido \\
poliacrilico, \\
eudragit, ácido \\
tartárico, ácido \\
sórbico, ácido \\
benzoico e \\
pigmentos
\end{tabular} & $\begin{array}{l}\text { Água, copolímero } \\
\text { de ácido acrilico e } \\
\text { ácido maleico, } \\
\text { ácido tartárico e } \\
\text { ácido benzoico }\end{array}$ & $\begin{array}{l}\mathrm{CIV} \\
\text { convencional }\end{array}$ \\
\hline Maxxion R & FGM & \begin{tabular}{|l|} 
Vidro de \\
aluminofluorsilicato, \\
ácido \\
policarboxilico, \\
fluoreto de cálcio e \\
água
\end{tabular} & Ácido poliacrilico & CIV convenional \\
\hline Vitremer & 3M ESPE & $\begin{array}{l}\text { Cristais de } \\
\text { fluoraluminiosili - } \\
\text { cato, persulfato de } \\
\text { potássio, ácido } \\
\text { ascórbico e } \\
\text { pigmentos }\end{array}$ & $\begin{array}{l}\text { Ácido } \\
\text { polialcenoico, } \\
\text { grupos } \\
\text { metacrilatos, } \\
\text { água, HEMA, } \\
\text { canforoquinona }\end{array}$ & $\begin{array}{l}\text { CIV modificado } \\
\text { por resina }\end{array}$ \\
\hline Vitro Molar & DFL & $\begin{array}{l}\text { Silicato de Bário e } \\
\text { Alumínio, ácido } \\
\text { poliacrilico } \\
\text { desidratado e óxido } \\
\text { de ferro }\end{array}$ & $\begin{array}{l}\text { Ácido poliacrilico, } \\
\text { ácido tartárico e } \\
\text { água destilada. }\end{array}$ & $\begin{array}{c}\text { CIV } \\
\text { convencional }\end{array}$ \\
\hline
\end{tabular}

Dez espécimes de cada material foram manipulados seguindo as recomendações dos fabricantes e em seguida divididos em dois grupos $(n=5)$ de acordo com o tratamento (aplicação tópica de flúor com gel de flúor neutro a $2 \%$ e aplicação tópica de gel de flúor fosfato acidulado 1,23\%).

Para confecção dos espécimes foi utilizada uma matriz de nylon com cavidade central de $0,5 \mathrm{~mm}$ de diâmetro por $2 \mathrm{~mm}$ de espessura. Após o proporcionamento e espatulação, o material foi inserido na cavidade central da matriz, até que o preenchimento da mesma fosse obtido, inserindo-se em seguida uma das extremidades de uma fita dental de $4 \mathrm{~cm}$ antes da presa do material. Na superfície da matriz foi posicionada a tira matriz de poliéster a fim de se obter maior lisura superficial padronizada, e lâmina de vidro, para exercer pressão durante a presa. A fotoativação foi realizada com aparelho de luz XL 2500 (3M ESPE) para o cimento modificado por resina - Vitremer.

Os espécimes foram armazenados em umidificador a $37^{\circ} \mathrm{C}$ e $100 \%$ de umidade relativa por 24 horas. Para os grupos onde não foi realizado a fotoativação, o espécime foi removido da matriz após 20 minutos e armazenado conforme descrito. Após o período de presa inicial, os espécimes foram imersos em água deionizada e contidos durante 24 horas em recipientes plásticos de poliestireno $(34 \mathrm{~mm}$ x 20 $\mathrm{mm}$ ), com tampa flexível. $\mathrm{Na}$ tampa do recipiente foi utilizada cera utilidade para fixar a extremidade

da fita dental e manter o espécime suspenso.

Um ensaio de rugosidade em rugosímetro (Surftest SJ-401 - Mitutoyo, Japão) foi efetuado após o período de armazenagem em água deionizada por 24 horas, contadas a partir da obtenção dos espécimes, sendo realizadas três leituras na superfície de cada espécime e a média registrada.

Para realização do ensaio de rugosidade os seguintes parâmetros de teste foram utilizados: tolerância - valores extremos a serem considerados na leitura (T mínimo $=0,001 \mu \mathrm{m} ; \mathrm{T}$ máximo $=8,00 \mu \mathrm{m})$; limite de tracejamento - extensão real percorrida pelo apalpador $(\mathrm{Lt}=4,0 \mathrm{~mm})$; limite da extensão considerada na leitura $(\mathrm{Lm}=4,2 \mathrm{~mm})$; Cut off - filtragem, minimizando a interferência de ondulação da superfície $(\mathrm{Lc}=0,8 \mathrm{~mm})$.

Os espécimes para o ensaio de rugosidade de superfície foram individualmente adaptados sobre uma placa de vidro com cera utilidade, com o auxílio de uma prensa e carga de $0,5 \mathrm{kgf}$ durante $3 \mathrm{~s}$. Em seguida foram levados ao rugosímetro com as seguintes condições de teste: $\mathrm{Lc}-0,8 \mathrm{~mm}$ e velocidade de $0.5 \mathrm{~mm} / \mathrm{s}$. A leitura considerada foi a média aritmética entre picos e vales (RA), percorridos numa trajetória realizada pelo apalpador mecânico de 4,0 $\mathrm{mm}$. Em cada espécime, foram feitas aleatoriamente três leituras, totalizando 120 leituras iniciais. Finalmente, os dados obtidos foram analisados estatisticamente de acordo com o teste de Turkey e teste T em nível de 5\% de significância.

Os espécimes foram então moldados com silicone por adição (Elite H-D, Zhermack) pesada e leve pela técnica do reembasamento ou dupla moldagem. Em seguida, os espécimes foram submetidos aos tratamentos com aplicação tópica de flúor com gel de flúor neutro a $2 \%$ e aplicação tópica de gel de flúor fosfato acidulado 1,23\% por 1 minuto. Sequencialmente foram realizadas novas medições da rugosidade de superfície, seguida de novas moldagens com silicone por adição pesada e leve pela técnica do reembasamento, à maneira descrita anteriormente. 
Em seguida foram confeccionados modelos dos espécimes com resina epóxica, representantes do período antecessor e sucessor aos tratamentos com os géis de flúor. As réplicas receberam cobertura de liga de ouro-paládio, sob alto vácuo, para observação em Microscopia Eletrônica de Varredura (MEV).

\section{Resultados}

Após o tratamento dos espécimes com gel de fluoreto de sódio neutro, os valores de rugosidade superficial e morfologia de superfície não diferiram dos encontrados antes do tratamento, para todos os materiais avaliados, considerando o nível de significância de 5\% pelo teste T. Os cimentos de ionômero de vidro Ketac Molar Easy Mix e Vitremer não diferiram estatisticamente entre si quanto à rugosidade superficial, após aplicação tópica de gel de flúor neutro, e, consequentemente, quanto à morfologia de superfície. Porém, ambos demonstraram diferenças morfológicas em relação aos grupos Vitromolar e Maxxion, que apresentou maior rugosidade superficial, seguido do Vitro Molar.

No entanto, após o tratamento das amostras com o flúorfosfato acidulado, os cimentos ionoméricos apresentaram uma variação significativa do padrão morfológico superficial analisado. De acordo com os resultados obtidos, o Maxxion apresentou a maior alteração do seu padrão morfológico, seguido em ordem decrescente de alteração dos grupos Ketac Molar Easy Mix, Vitro Molar e Vitremer (figuras 1 e 2).

Os resultados observados em MEV foram sedimentados através da análise em rugosímetro, que avaliou estatisticamente as alterações micromorfológicas produzidas em superfície (figura 3 e 4).

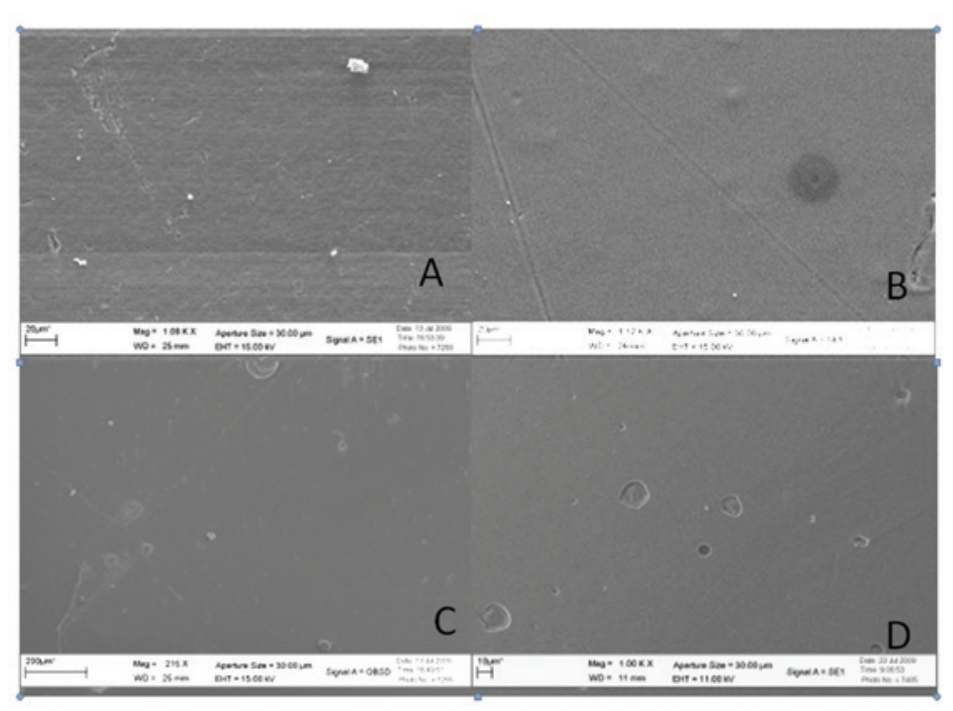

Figura 1. Fotomicrografia eletrônica de varredura do cimento de ionômero de vidro Maxxion R (A), Vitromolar (B), Ketac Molar Easy Mix (C), Vitremer (D), antes do tratamento

Figura 2. Fotomicrografia eletrônica de varredura do cimento de ionômero de vidro Maxxion R (A), Vitromolar (B), Ketac Molar Easy Mix (C), Vitremer (D), após tratamento com gel de flúor acidulado

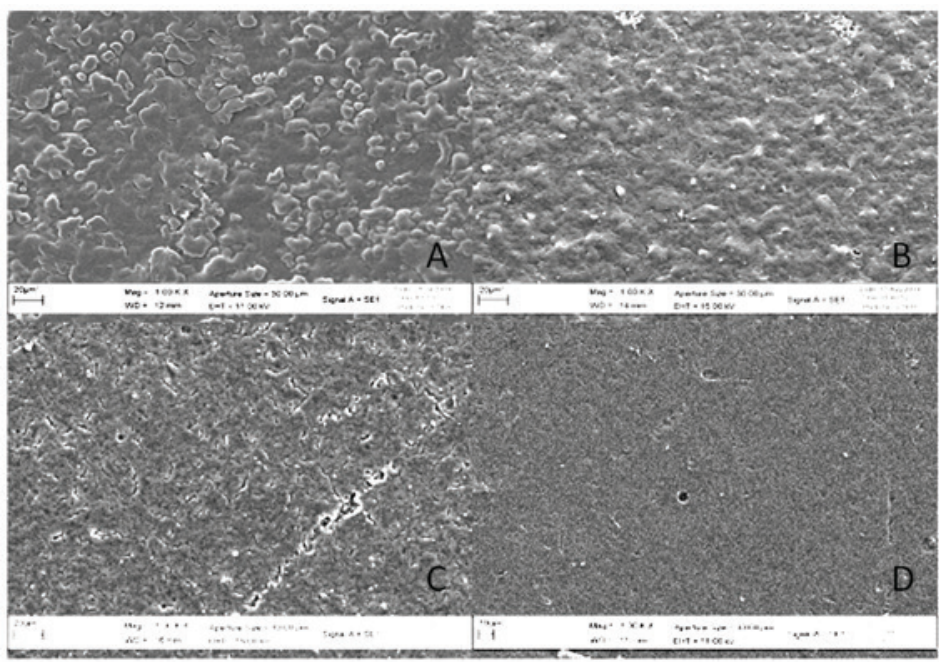




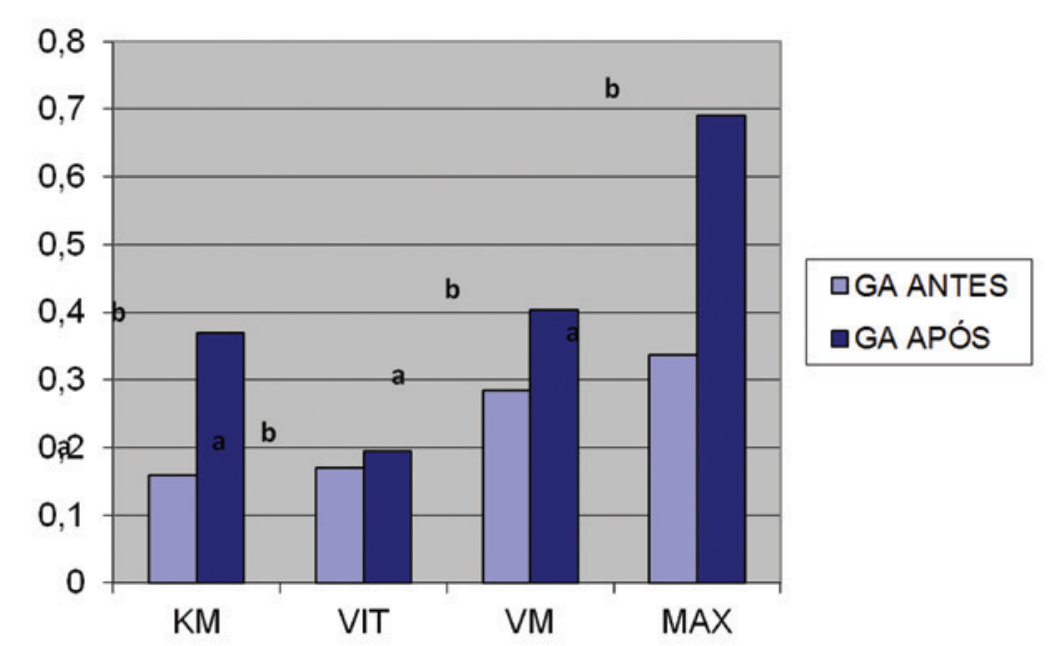

Figura 3. Rugosidade de superfície dos espécimes por material antes e após o tratamento com flúor fosfato acidulado a $1,23 \%$

* Letras distintas diferem entre si ao nível de $5 \%$ de significância pelo teste de T

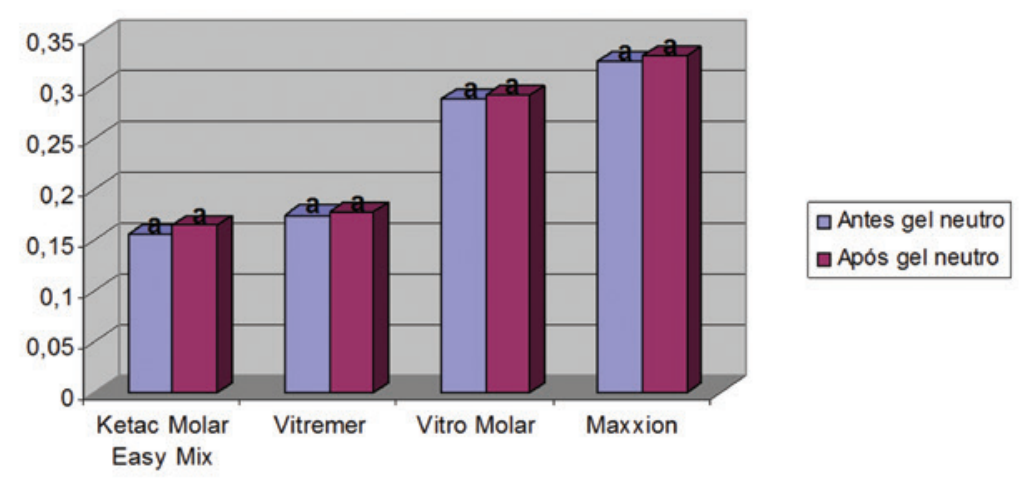

Figura 4. Rugosidade de superfície dos espécimes por material antes e após o tratamento com gel de fluoreto de sódio neutro a $2 \%$

*Letras semelhantes não diferem entre si ao nível de 5\% de significância pelo teste de T

\section{Discussão}

A aplicação tópica de flúor tornou-se uma medida preventiva para toda a população e pode ser considerada uma boa maneira de recarga de flúor pelas restaurações de cimentos de ionômero de vidro convencionais ou modificados por resina (9). Entretanto, o ácido proveniente do flúor fosfato acidulado pode causar efeitos adversos nas propriedades superficiais destes materiais restauradores, o que condiz de fato, aos resultados obtidos no presente estudo (10).

Segundo alguns pesquisadores o gel de flúor fosfato acidulado forma mais fluoreto de cálcio no esmalte do que o gel neutro, sendo mais eficiente em reduzir a desmineralização do esmalte e, portanto, sendo preferíveis à aplicação de géis neutros (11).

No entanto, vários estudos demonstraram que o flúor gel atua tanto na estrutura dentária quanto no material restaurador, modificando a micromorfologia da superfície do material, deixando-o mais rugoso, além de levar à perda da dureza do material, corroborando aos resultados encontrados referentes ao tratamento com gel de fluorfosfato acidulado a $1,23 \%$ $(9,12,13,14)$. A degradação promovida pela aplicação do flúor gel fosfato acidulado é provavelmente causada pela lixiviação dos cátions $\mathrm{Na}$, $\mathrm{Ca}$ e $\mathrm{Al}$ que formam a matriz e a formação de complexos com os ânions ácidos (15). As características das partículas de carga, tais como a sua composição, forma e tamanho, bem como o emaranhamento da resina e matrizes inorgânicas, desempenham um papel importante no comportamento de materiais restauradores submetidos a aplicações tópicas de flúor (16-18).

A dissolução da matriz de polissais com maior liberação de flúor pode ser entendida como positiva em situações clínicas de adequação do meio bucal, em que as restaurações realizadas têm caráter provisório, e o paciente apresenta alta atividade de cárie. Entretanto, nos casos de tratamento restaurador atraumático (TRA), para qual o cimento Ketac Molar Easy Mix 
é indicado, essa dissolução da matriz e alteração superficial tem efeito deletério, já que a longevidade da restauração é uma característica necessária, uma vez que as restaurações realizadas através dessa técnica têm caráter permanente (9).

Segundo estudos de FIROOZMAND \& ARAÚJO (19), as alterações na micromorfolgia são ainda mais evidentes nos cimentos de ionômero de vidro convencionais e modificados por resina quando expostos ao flúor fosfato acidulado em comparação com o flúor neutro. Isso se deve ao fato de que o flúor fosfato acidulado contém ácido fosfórico na sua composição e que é responsável por condicionar as partículas de vidro e liberar os principais cátions constituintes da matriz, provocando erosão química do material com dissolução da sua superfície, diminuindo a longevidade da restauração $(9,20)$. Estudos de BENDERLI, GOKÇE, KASAKM (11) e GILL \& PATHAK (14) demonstraram que quando há a presença de monômeros resinosos na estrutura do material ocorre possivelmente uma diminuição dos efeitos erosivos do gel de flúor fosfato acidulado, corroborando aos resultados relativos ao Vitremer. Nos cimentos resinosos modificados por resina, a reação de polimerização ácido-base é complementada por uma segunda reação fotoativada ou quimicamente ativada. Nestes materiais foram adicionados monômeros e/ou grupos metacrilatos pendentes, pequena quantidade de componentes resinosos, semelhantes ao Bis-GMA ou HEMA (21). A presença desses componentes pode ser a razão para a maior resistência dos CIVs modificados por resina ao desafio ácido (14).

Assim como demonstrado nos resultados obtidos, segundo a superfície dos CIVs pode ser significativamente alterada quando em contato com os géis de flúor e tal característica é de importância clínica uma vez que esses produtos são recomendados com estratégia preventiva nos programas de saúde bucal (10). Pacientes que possuem restaurações de ionômero de vidro apresentam risco de aumentar a rugosidade superficial do material devido à vulnerabilidade ao ácido do flúor fosfato acidulado, e essa mudança na textura superficial pode afetar a longevidade da restauração.

Aliado a este fato, não só a ação de géis de flúor acarreta defeitos na micromorfologia das restaurações. Oscilações químicas da cavidade bucal podem acarretar alterações nas propriedades dos cimentos ionoméricos, bem como modificar a superfície do cimento reduzindo a dureza e propiciando maior desgaste superficial. O pH salivar no meio bucal, por sua vez, pode variar em virtude da produção de ácidos por micro-organismos do biofilme dental durante o metabolismo dos carboidratos provenientes da dieta. Dessa forma, uma limitação dos CIVs está relacionada com a ação de soluções com baixo $\mathrm{pH}$ as quais podem deteriorar a superfície do material, tornando-o mais susceptível à falha clínica (22), fato que foi pronunciado no estudo em questão.

A despeito da solução de armazenagem utilizada no estudo, a sorção de água pelos cimentos de ionômero de vidro também está diretamente relacionada ao aumento do volume do material com ganho de massa, o que pode levar a alterações das propriedades mecânicas e morfológicas do material. Vários fatores influenciam o coeficiente de sorção da água, dentre eles a natureza hidrófila e o volume da porção resinosa no material (23). Para GALAN JÚNIOR (24), os CIVs são bastante sensíveis ao contato prematuro com água, pois esta causa alterações nas propriedades físicas e mecânicas dos cimentos convencionais, como absorção e erosão, tornando o material em questão passível de fraturas.

As diferenças de composição são capazes de determinar desigualdades no comportamento de materiais cujos fabricantes são distintos. Assim, segundo PRAKKI et al. (25), a composição química do material representa importante papel nas suas propriedades. Segundo tais autores, a rugosidade de superfície pode estar relacionada à sorção de água, bem como solubilidade desses materiais nos meios. Além disso, o tamanho das partículas expostas à água, o grau de conversão, a densidade da cadeia, a presença de poros ou de sistemas de iniciação química e física de polimerização têm importante papel neste processo.

\section{Conclusão}

A rugosidade superficial e as alterações da micromorfologia dos cimentos de ionômero de vidro demonstraram-se diretamente relacionadas à ação tópica de géis acidulados, que podem levar a uma dissolução superficial da restauração, diminuindo propriedades mecânicas e estéticas da mesma.

Dentro das limitações de um estudo in vitro, observou-se que os cimentos de ionômero de vidro convencionais sofreram maior influência do efeito condicionador proporcionado pelo flúor acidulado nas alterações morfológicas de superfície, quando comparado ao cimento de ionômero de vidro modificado por resina. A aplicação tópica de gel de flúor neutro, no entanto, não provocou alterações morfológicas visíveis nos materiais avaliados em sua totalidade.

A aplicação tópica de flúor acidulado apresentou alterações de superfície em todos os materiais avaliados, no entanto, estas foram mais pronunciadas para o cimento de ionômero de vidro Maxxion e Ketac Molar Easy Mix, no entanto, estudos in vivo a respeito das alterações superficiais provocadas aos CIVs são necessários, a fim de consolidar o conhecimento teórico-científico abordado na temática em questão. 


\section{Referências ::}

1. PARADELLA, TC. Cimentos de ionômero de vidro na Odontologia moderna. Rev Odont UNESP 2004;33(4):157-61.

2. PEDRINI, D, GAETTI-JARDIM JR, E, MORI, GG. Influência da aplicação de flúor sobre a rugosidade superficial do ionômero de vidro Vitremer e adesão microbiana a este material. Pesq Odont Bras 2001;15(1):70-6.

3. GANDOLFI, MG et al. Fluoride release and absorption at different $\mathrm{pH}$ from glass ionomer cements. Dental materials 2005;22(5):441-9.

4. ITIOTA, T, CARRICK, TE, YOSHIYAMA, M, et al. Fluoride release and recharge in giomer, compomer and resin composite. Dental materials. 2004;20:789-95.

5. MIRANDA, LA, WEILDLICH, P, SAMUEL, SMW, et al. Fluoride release from restorative materials coated with an adhesive. Brazilian Dental Journal 2002;13(1):39-43.

6. PEDRINI, D, DELBEM, ACB, FRANÇA, JCM, et al. Fluoride release from restorative materials before and after a topical application of fluoride gel. Pesq Odontol Bras 2003;17(2):137-41.

7. DE WITTE, MJC, DE MAEYER, EAP, VERBEECK, RMH. Surface roughening of glass ionomer cements by neutral NAF solutions. Biomat 2003; 24(11):1995-2000.

8. SILVA, RC, ZUANON, ACC. Surface Roughness of Glass Ionomer Cements Indicated for Atraumatic Restorative Treatment (ART). Braz Dent J 2006; 17(2):106-9.

9. WILDE, MGK, et al. Influence of $0,05 \%$ sodium fluoride solutions on microhardness of resin modified glass ionomers cements. J Mater Sci Mat Med 2006;17:868-73.

10. SALAMA, FS, ELMALLAKH, BF. Effect of APF application on the microhardness of light-activated restorative materials. The Saudi Dental Journal 1996;8(2)

11. BENDERLI, Y, GOKÇE, K, KASAK, M. Effect of APF gel on micromorphology of resin modified glass ionomer cements and flowable comomers. Jornal of Oral Rehabilitation 2005;(32):669-75.

12. CURY, JA et al. The importance of fluoride dentrifícios to the current dental caries prevalence in Brazil. Brazilian Dental Journal 2004;15(3): 167-73.

13. GARCIA-GODOY, $\mathrm{F}$ et al. Effect of APF minute-foamon the surface roughness, hardness and micromorphology of high-viscosity glass iono- mers. J Dent Child 2003; 70(1):19-23.

14. GILL, NC, PATHAK, A. Comparative evaluation of the effect of topical fluorides on the microhardness of various restorative materials: an in vitro study. J Indian Soc Pedod Prev Dent 2010; 28(3):193-9.

15. EL-MALLAKH, BF, SARKAR, NK. Fluoride release from glass ionomer cements in deionized water and artificial saliva. Dent Mater $1990 ; 6: 118-22$.

16. MCCABE, JF. Resin-modified glass-ionomers. Biomaterials 1998; 19(6):521-7.

17. DE WITTE, AM, DE MAEYER, EA, VERBEECK, RM. Surface roughening of glass ionomer cements by neutral $\mathrm{NaF}$ solutions. Biomaterials 2003;24(11):1995-2000.

18. WIEGAND, A, BUCHALLA, W, ATTIN, T. Review on fluoride-releasing restorative materials-fluoride release and uptake characteristics, antibacterial activity and influence on caries formation. Dent Mater 2007; 23(3): 343-62.

19. FIROOZMAND, LM, ARAÚJO, MAM. Ação do flúor fosfato acidulado a $1,23 \%$ sobre a resina composta: microdureza. Ciência Odontológica Brasileira 2006; 9(4): 27-34.

20. SETTY, JV, SINGH, S, REDDY, VV. Comparison of the effect of topical fluorides on te commercially available conventional glass ionomers, resin modified glass ionomers and polyacid modified composite resins: an in vitro study. J Indian Soc Pedo Prev Denta 2003; 21 (2): 55-69.

21. ABATE, PF, BERTACCHINI, SM, GARCIA-GODOY, F, et al. Barcoll hardness of dental materials treated with an APF foam. Journal of Clinical Pediatric Dentistry 2001;25(2):143-6.

22. MOHAMED-THAIR, MA, YAP, AU. Effects of $\mathrm{pH}$ on the surface texture of glass ionomer based/containing restorative materials. Oper Dent 2004;29:586-91

23. KANCHANAVASITA, W, ANSTICE, HM, PEARSON, GJ. Long-term surface micro-hardness of resin-modified glass ionomers. Journal of Dentistry 1998:26:707-12.

24. GALAN JÚNIOR, J. Materiais Dentários: O essencial para o estudante e o clínico geral. São Paulo: Santos, 1999. 160p.

25.PRAKKI, A. et al. Influence of Ph environment on polymer based dental material properties. Journal of Dentistry 2005;33(2): 91-8.

Recebido em: 17/07/2014 / Aprovado em: 19/08/2014

Renally Bezerra Wanderley e Lima

Rua Doutor Otávio Teixeira Mendes, n 1154, apto. 61

Piracicaba/SP, Brasil - CEP: 13419-220

E-mail: renallywanderley@gmail.com 